\author{
Marquette University \\ e-Publications@Marquette
}

Biomedical Engineering Faculty Research and

Publications

Biomedical Engineering, Department of

3-2005

\title{
An In Vitro Comparison of the Rake Angles Between K3 and ProFile Endodontic File Systems
}

David Y. Chow

Marquette Universtiy

Sheila E. Stover

Marquette University

James Bahcall

Marquette University

Andris Jaunberzins

Marquette University

Jeffrey M. Toth

Marquette University, jeffrey.toth@marquette.edu

Follow this and additional works at: https://epublications.marquette.edu/bioengin_fac

Part of the Biomedical Engineering and Bioengineering Commons

\section{Recommended Citation}

Chow, David Y.; Stover, Sheila E.; Bahcall, James; Jaunberzins, Andris; and Toth, Jeffrey M., "An In Vitro Comparison of the Rake Angles Between K3 and ProFile Endodontic File Systems" (2005). Biomedical Engineering Faculty Research and Publications. 558.

https://epublications.marquette.edu/bioengin_fac/558 
Marquette University

\section{e-Publications@Marquette}

\section{Biomedical Engineering Faculty Research and Publications/College of Engineering}

This paper is NOT THE PUBLISHED VERSION; but the author's final, peer-reviewed manuscript. The published version may be accessed by following the link in the citation below.

Journal of Endodontics, Vol. 31, No. 3 (2005): 180-182. DOI. This article is (C) Elsevier and permission has been granted for this version to appear in e-Publications@Marquette. Elsevier does not grant permission for this article to be further copied/distributed or hosted elsewhere without the express permission from Elsevier.

\section{Contents}

Abstract. 2

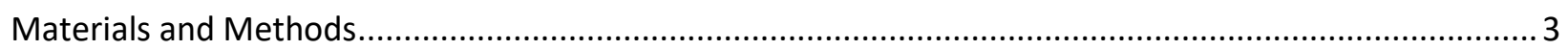

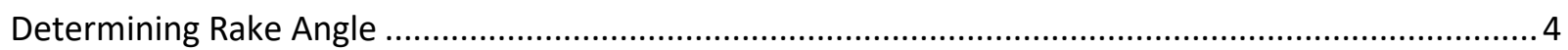

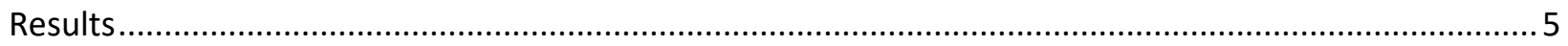

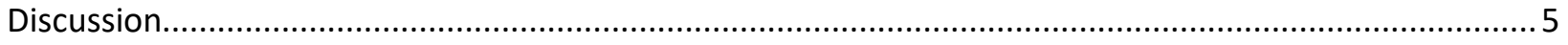

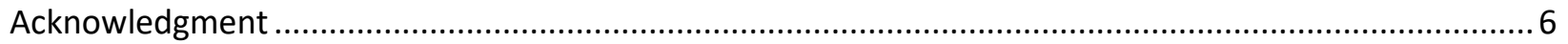

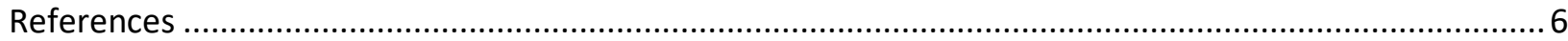

\section{An In Vitro Comparison of the Rake Angles Between K3 and ProFile Endodontic File Systems}


David Y. Chow

Department of Endodontics, Marquette University School of Dentistry, Milwaukee, WI

Sheila E. Stover

Department of Endodontics and the Department of General Dental Sciences/Biomaterials, Marquette University School of Dentistry, Milwaukee, WI

James K. Bahcall

Department of Endodontics and the Department of General Dental Sciences/Biomaterials, Marquette University School of Dentistry, Milwaukee, WI

Andris Jaunberzins

Department of Endodontics and the Department of General Dental Sciences/Biomaterials, Marquette University School of Dentistry, Milwaukee, WI

Jeffrey M. Toth

Department of Endodontics and the Department of General Dental Sciences/Biomaterials, Marquette University School of Dentistry, Milwaukee, WI

\section{Abstract}

The purpose of this study was to compare rake angles of the ProFile and K3 file systems. Twenty-five 40/0.06 taper files were obtained for each system. Five files from the same manufacturer were placed perpendicularly into a vial of Epoxicure Resin and left to set for $24 \mathrm{~h}$. The set-ups were removed from the vials and each were sectioned $5 \mathrm{~mm}$ from the tip of the files and polished. A photomicrograph was taken of each file with 100x magnification. Five sets of ProFile and five sets of K3 files were processed in this manner. Images were captured digitally, and rake angles of each file were measured. Multivariate ANOVA found a significant difference $(p<0.001)$ among the three negative rake angles of the ProFile system compared with the K3 system.

One of the primary goals of nonsurgical root canal treatment is the removal of pulp tissue or necrotic debris from the root canal system. The complete removal of tissue or debris is dependent on chemomechanical cleaning and shaping of the canals. ${ }^{-1}$ Once completed, gutta-percha and sealer are used to provide a three dimensional obturation of the root canal system. ${ }^{1}$

Endodontic files provide the mechanical cleaning and shaping aspect of canal preparation. Today's files are designed to allow for better debris removal, increased cutting efficiency, better flexibility, and more resistance to separation. $, 2,3,4$, Some manufacturers have reported positive rake angles help to increase the cutting efficiency of a file. $\frac{6}{}$

SybronEndo have marketed their K3 files (SybronEndo, Orange, CA) as positive rake angle files. They report that files with a positive rake along with a variable helical flute angle provide better cutting efficiency and debris removal from the canal system. ${ }^{-}$The ProFile (Dentsply, International, Inc., Tulsa, OK) file system is marketed as negative rake angle files.,$\frac{6}{7}$ This type of file system has been reported to be less efficient in cutting dentin. $-\underline{T}$ The negative rake angle design allows for planing of the dentinal walls instead of cutting. $\stackrel{7}{-}$ The objective of this study is to measure and provide a comparison of the rake angles between ProFile and K3 files. 


\section{Materials and Methods}

Twenty-five new 40/0.06 taper ProFile and 25 new 40/0.06 taper K3 files were examined. Five files from the same manufacturer were bonded together with an adhesive, Zapit (DVA, Anaheim, CA) at the handles. Care was taken to ensure that each file was parallel to each other. Ceramic sticks were then bonded perpendicularly to the handles of the files (Fig. 1) to ensure the tips of the files were perpendicular to the floor of the sample. This ensured that an accurate cross-section of the files could be determined. Epoxicure Resin (Buehler, Lake Bluff, IL) and Epoxicure Hardener (Buehler) were mixed as specified by the manufacturer and placed in a vial in a vacuum chamber at $95 \mathrm{~mm} \mathrm{Hg}$ for $5 \mathrm{~min}$. The bonded files were then inserted into the vial containing the resin, again ensuring that the file was perpendicular to the base of the resin (Fig. 1). The sample was then placed in the vacuum chamber at 95 $\mathrm{mm} \mathrm{Hg}$ for $5 \mathrm{~min}$, ensuring minimal porosity in the resin. The sample was allowed to set on the counter top for $24 \mathrm{~h}$ per manufacturer's directions. Five sets of K3 files and five sets of ProFile files were made in this manner. The set-ups were then removed from the vials and measuring from the tip of the file, a \pm 5 $\mathrm{mm}$ section was removed using a Duomet II Grinder (Buehler). The section face was polished with Handimet Grinder (Buehler) at grit levels of 240, 320, 400, and 600. Five strokes in two perpendicular directions of the four sequential grit levels were completed. Diamond paste of $0.05 \mu$ was used as a final polish with an Ecomet $\mathrm{V}$ (Buehler) polishing machine. Care was taken to not over-polish the specimen to prevent rolling of the files' edges.

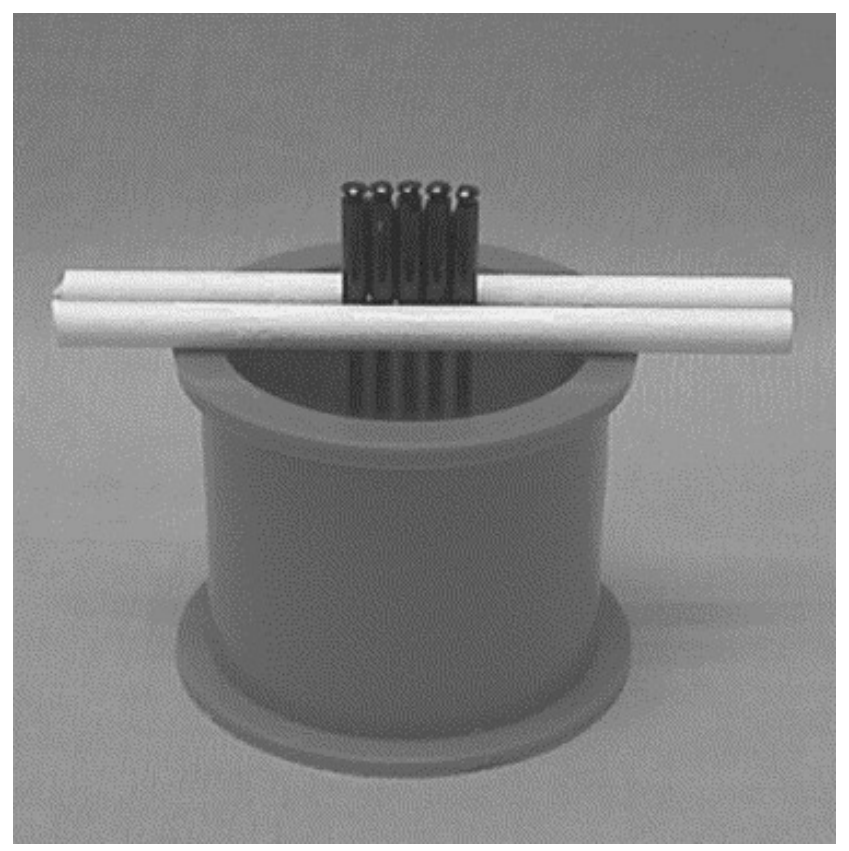

Figure 1. Ceramic sticks bonded to the files and placed perpendicularly into the vial containing Epoxicure (Buehler, Lake Bluff, Illinois) Resin. The tips of the files were touching the floor of the vial.

The coronal segments of the files were then examined under the light microscope at 100x magnification. Polaroid pictures using Polapan Pro 100 black and white instant sheet film (Polaroid Corporation, Cambridge, MA), were taken of each file. Pictures were then digitally captured on Image-Pro Plus Version 4.0 Software (Media Cybernetics Inc., Silver Spring, MD) using a color video camera (Hyper HAD CCD-IRIS/RGB, Sony, Tokyo, Japan) with a $24 \mathrm{~mm}$ 1:2.8 lens (Nikon, Tokyo, Japan). Image-Pro Plus 
Version 4.0 Software (Media Cybernetics Inc., Silver Spring, MD) was then used to determine the rake angles of the files.

\section{Determining Rake Angle}

The rake angle on each cutting tip was averaged and both file types were compared. All of the pictures taken of the K3 files were taken in the same orientation, with the third radial land $\left({ }^{6}\right)$ centered in the bottom of the field of view. As stated earlier, the coronal segments of the files were examined. This explains the rotation of the file in a counter-clockwise direction as depicted in Fig. 2.

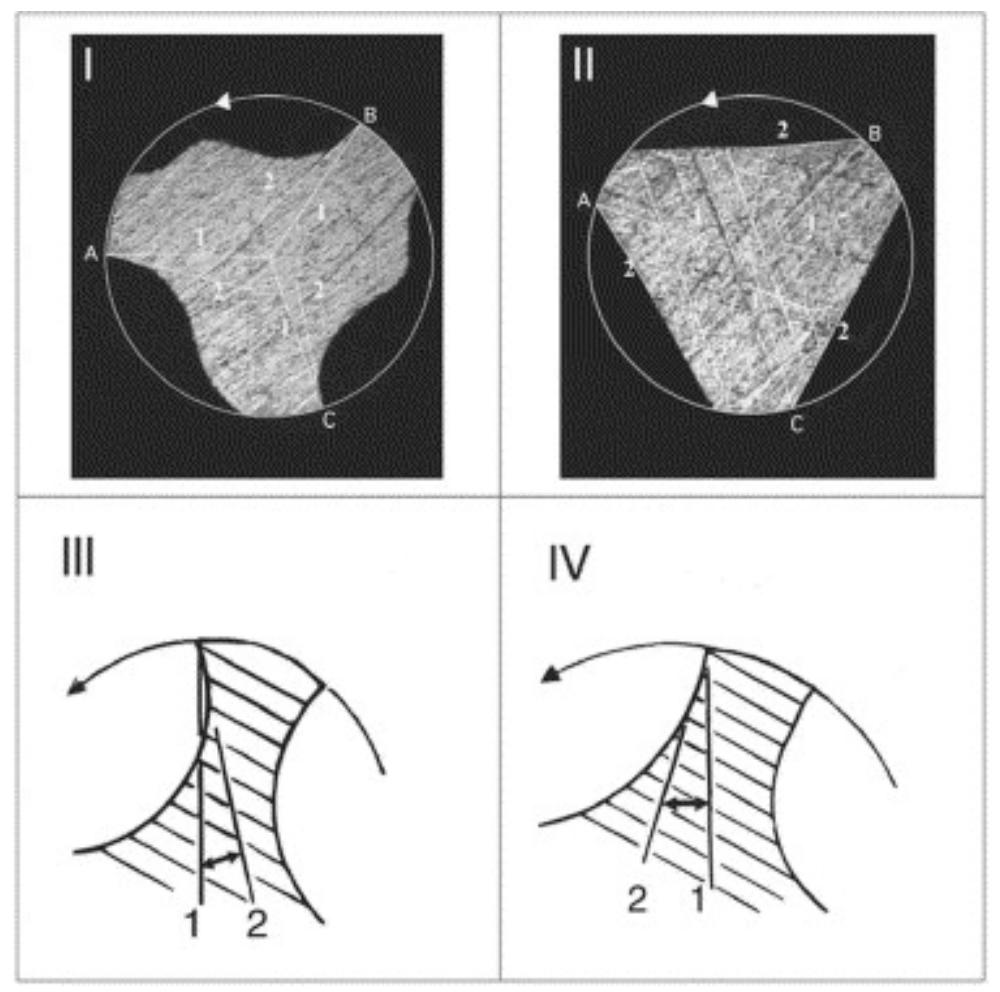

Figure 2. Coronal segment of K3 (Sybronendo, Orange, CA) file with tangent lines drawn depicting negative rake angles at all three cutting tips (I). Coronal segment of ProFile (Dentsply, International, Inc., Tulsa, OK) file with tangent lines drawn depicting negative rake angles at all three cutting tips (II). Diagramatic representation of a positive rake angle cutting tip (III). Diagramatic representation of a negative rake angle cutting tip (IV) III and IV adapted from Park and Lakes, Biomaterials: An Introduction. 2nd ed. ( $(\stackrel{9}{)}$.

Rake angle is the angle subtended by two intersecting lines. The first (Line 1 ) is drawn between the cutting tip and the geometric center of the instrument, and the second (Line 2 ) is tangential to the curve of the cutting face at its tip (Fig. 2). A positive rake angle occurs when the peripheral line segment (Line 1 ) is located in front of the cutting face (Fig. $2 \mathrm{III}$ ). A negative rake angle occurs when the peripheral line segment (Line 1 ) is located behind the cutting face (igig. 2 IV). $, .9, \underline{10}$

In this study, the geometric center was determined with the aid of the computer software. A circle was drawn with the software around the scanned image of the file. Care was taken to ensure that the cutting tips contacted the circle and the software determined the geometric center of the file. Lines 1 and 2 
were drawn using the software line function and placed according to the definition of determining rake angles.

\section{Results}

The average rake angles of the K3 40/0.06 taper files were $-16( \pm 5)$ degrees for angle $A,-13( \pm 3)$ degrees for angle $\mathrm{B}$ and -15 ( \pm 5 ) degrees for angle $\mathrm{C}$ (Fig. 2 I). All of the $\mathrm{K} 3$ files were determined to have negative rake angles. For the ProFile 40/0.06 taper files, the average rake angles were $-43( \pm 2)$ degrees for angle $A,-43( \pm 3)$ degrees for angle $B$, and $-43( \pm 2)$ degrees for angle $C$ (Fig. 2 II). All the ProFile files were determined to have negative rake angles. Statistical analysis was performed. A multivariate ANOVA found a significant difference $(p<0.001)$ among the three negative rake angles of the ProFile compared with K3 files.

\section{Discussion}

There is no research reported in the current endodontic literature that specifically compares the rake angles between these nickel-titanium rotary file systems. The results of our study demonstrated a negative rake angle for the $\mathrm{K} 3$ file. To determine the rake angle of a file, a cross-sectional representation of the file is required. To obtain an accurate cross-section, the files were embedded in acrylic resin and then sectioned. $2,3,4,5,7$ The use of the harder Epoxicure resin, instead of methyl methacrylate resin, to mount the files was to minimize the rolling of the file's edges during the cross-sectional preparation. This would provide a more accurate representation of the file.

The difference between the rake angles of the K3 in the literature and in this study could be a result of the method in which rake angles are determined. The concept of a positive or a negative rake angle in endodontic literature has frequently been based on a qualitative visual assessment of the file's crosssection. This visual evaluation is not an accurate way of determining the actual rake angle of these files. By direct measurement, as in the method used by Guppy et al. $\stackrel{?}{-}$ or by using computer software, as it was done in this study, it is possible to provide an accurate interpretation of a file's rake angles.

The reason that visual interpretation of the $\mathrm{K} 3$ file is inaccurate in determining rake angle may be because of the asymmetrical nature of the file. The asymmetrical design prevents an accurate visualization of the axis of the file. The rake angle of a rotary cutting flute is defined as the angle subtended by two intersecting lines. Line 1 being a line drawn between the cutting tip and the geometric center of the instrument, and Line 2 being a line tangential to the curve of the cutting face at its tip (Fig. 2). Thus without knowing the radius/axis of a file, it would be impossible to determine the rake angle. Quantec (SybronEndo) file is another asymmetrical file that is reported to have a slightly positive rake angle. In the study conducted by Guppy et al. ${ }^{-}$care was taken to identify the central axis of the file, it was determined that the Quantec file also has a negative rake angle.

It is important to also note that the discrepancy in the three angles within the K3 files could be caused by several of the following factors. During the sectioning of the files, some rolling of the edges of the files may have occurred. Precautions taken during the study would help to minimize this effect. Manufacturing discrepancies during the production of the files could also have caused the difference in these three rake angles. Another reason may be the files were manufactured to have different rake angles in all three cutting tips. 
The importance of rake angles in endodontic literature has not yet been clearly defined. There are references that suggest positive rake angle increase the cutting efficiency and therefore takes less energy to cut dentin. $\underline{8}, \underline{10}, \underline{11}$ However, there are no studies that isolate rake angle as the only variable that affects cutting efficiency. Bergman et al..$\underline{10}$ reported that there are no clear standards to date that determine the cutting effectiveness of endodontic files.

Many machine tools, including taps, milling cutters and drills, have multiple cutting edges with different radial rake angles, axial rake angles, clearance angle and relief angles. $\frac{12}{}$ Another consideration is if nickel-titanium alloy has sufficient edge strength to support an effective and durable positive rake angle. With the diminutive size of the endodontic files, it may only be possible to create a neutral or close to neutral rake file system with the nickel-titanium alloy. A combination of these factors and the type of metal used as the cutter and the surface to be cut will influence the cutting efficiency of a file.

From the results of the study it can be concluded that both the $\mathrm{K} 3$ and ProFile systems are negative rake angle files. Statistical analysis using the multivariate ANOVA, the quantitative analysis shows a significant difference $(p<0.001)$ between the angles of the two file systems. Further studies are needed to evaluate the clinical benefits of a positive versus a negative rake angle file.

\section{Acknowledgment}

The authors would like to thank Dr. Naveen Bansal for his assistance with the statistical analysis of data.

\section{References}

Schilder H. Filling root canals in three dimensions. Dent Clin North Am (1967), pp. 723-744

Schäfer E. Relationship between design features of endodontic instruments and their properties. Part 1: cutting efficiency. J Endod, 25 (1999), pp. 52-56

Miserendino $L$, Moser JB, Osetek EM. Cutting efficiency of endodontic instruments. Part 1: a quantitative comparison of the tip and fluted regions. J Endod, 11 (1985), pp. 435-441

Krupp J, Brantley W, Gerstein H. An investigation of the torsional and bending properties of seven brands of endodontic files. J Endod, 10 (1984), pp. 372-380

Anderson J, Corcoran J, Craig R. Cutting ability of square versus rhombus cross-sectional endodontic files. J Endod, 11 (1985), pp. 212-217

K3 ${ }^{\circledR}-3^{\text {rd }}$ generation rotary NiTi file for precision endodontics. SybronEndo Sales Sheet.

Guppy DR, Curtis RV, Pitt Ford TR. Dentin chips produced by nickel-titanium rotary instruments. Endod Dent Traumatol, 16 (2000), pp. 258-264

Wildey WL, Senia S, Montgomery S. Another look at root canal instrumentation. Oral Surg Oral Med Oral Pathol, 74 (1992), pp. 499-507

Park JB, Lakes RS. Biomaterials: an introduction (2nd ed.), Plenum Publishing, New York (1992), pp. 297300

Bergmans L, Van Cleynenbreugel J, Wevers M, Lambrechts P. Mechanical root canal preparation with NiTi rotary instruments: rationale, performance and safety. Am J Dent, 14 (2001), pp. 324-333

Schäfer E, Florek H. Efficiency of rotary nickel-titanium K3 instruments compared with stainless steel hand K-Flexofile. Part 1: shaping ability in simulated curved canals. Int Endod J, 36 (2003), pp. 199-207

ASM: metals reference book (3rd ed.), ASM International, USA (1993), pp. 1-97 
